\title{
Liquid Crystalline and Fluorescent Properties of Semi-Rigid Poly(ester imide)s Derived from Bismethyl Ester and Bisalcohol Derivatives of $3,3^{\prime}, 4,4^{\prime}-$ Biphenyltetracarboxdiimide
}

\author{
Moriyuki SATO,${ }^{\dagger}$ Yoshimi NaKAmoto, and Nobue TANino \\ Department of Material Science, Faculty of Science and Engineering, Shimane University, \\ 1060 Nishikawatsu, Matsue-shi, Shimane 690-8504, Japan
}

(Received October 1, 2001; Accepted January 8, 2002)

\begin{abstract}
Thermotropic liquid crystalline and photoluminescent properties of semi-rigid homo- and copoly(ester imide)s composed of only both 3,3',4,4'-biphenyltetracarboxdiimide and aliphatic chains without traditional mesogens, which were prepared by transesterification of $N, N^{\prime}$-bismethyl ester derivatives and $N, N^{\prime}$-bisalcohols of $3,3^{\prime}, 4,4^{\prime}$ biphenyltetracarboxdiimide, were evaluated by differential scanning calorimetry (DSC), polarizing microscope observation, powder X-Ray analyses, UV-vis absorption and PL spectrum measurements. These measurements suggested that polymers having decamethylene chain neighboring the imide ring and decamethylene chain-rich copolymers tend to form nematic phase and that they show maximum absorbances and blue-emission maxima arising from the $3,3^{\prime}, 4,4^{\prime}$ biphenyltetracarboxdiimide both in solutions and in films.

KEY WORDS Liquid Crystalline Property / Photoluminescent Property / Semi-Rigid Poly(ester imide) / 3,3',4,4'-Biphenyltetracarboxdiimide / Transesterification / Nematic Phase / Differential Scanning Calorimetry / Blue-Emission /
\end{abstract}

Polyimides have not only excellent thermal, mechanical and chemical properties, but also various interesting physical properties such as nonlinear optical, liquid crystalline (LC) and fluorescent properties. ${ }^{1-4,34}$

Active works about synthesis and LC properties of the polyimides have been done by Kricheldorf and so on. ${ }^{5-16}$ We have also continued to prepare a series of semi-rigid thermotropic LC poly(ester imide)s and poly(imide carbonate)s and to discuss a relationship between polymer structure and LC property in the semi-rigid polyimides. ${ }^{17-30}$ There are basically two different approaches in order to obtain the thermotropic LC polyimides. The first approach is to prepare polymers constituted of symmetric aromatic diimide units such as 3,3',4,4'-biphenyltetracarboxdiimide and $3,3^{\prime \prime}, 4,4^{\prime \prime}$ - $p$-terphenyltetracarboxdiimide, and the seconds is to synthesize polymers having asymmetric aromatic imide structures like $N$-phenylphthalimide. The former polymer has low or poor mesogenic property compared with the latter. Most of them don't show LC properties without the presence of benzene ring next to the imide ring or conventional biphenyl mesogen in the main chain. The $3,3^{\prime \prime}, 4,4^{\prime \prime}$ $p$-terphenyltetracarboxdiimide unit is a better mesogen than the 3,3',4,4'-biphenyltetracarboxdiimide. ${ }^{26,27}$

In recent years, we developed semi-rigid homo- and copoly(imide carbonate)s made up of only the symmetric diimides $\left(3,3^{\prime}, 4,4^{\prime}\right.$-biphenyltetracarboxdiimide and/or 3,3", $4,4^{\prime \prime}$ - $p$-terphenyltetracarboxdiimide) and aliphatic chains without coexistence of the biphenyl moiety in the main chain and showed that the $3,3^{\prime \prime}, 4,4^{\prime \prime}$ - $p$-terphenyltetracarboxdiimide-rich polymers form thermotropic LC phases in spite of absence of the conventional mesogens..$^{28,29}$ The aliphatic chains next to the imide ring play an important role in the LC formation of the semi-rigid poly(imide carbonate)s. Kricheldorf et al. found that semi-rigid poly(ester imide)s derived from $N, N^{\prime}$-bisphenol ${ }^{13}$ or $N, N^{\prime}$-bisester derivative ${ }^{14}$ of $3,3^{\prime}, 4,4^{\prime}$-biphenyltetracarboxdiimide having benzene ring next to the imide unit form enantiotropic smectic phases. In the polymers longer spacers and aliphatic chains with odd numbers favored the LC formation of polymers. It is of interest to evaluate effect of aliphatic even or odd chains linked to the imide ring and total lengths or combination of aliphatic chains between two imide structures on the LC formation of semi-rigid poly(ester imide)s composed of only the symmetric diimide ring and aliphatic chains.

On the other hand, much attention has been paid to organic electroluminescent (EL) devices. ${ }^{31-33}$ The polyimides are made up of electron-donating and electron-withdrawing structural segments, which are efficient electron and hole conductors, and have a potential as light-emitting or charge transporting materials for the organic devices. ${ }^{3}$ Mikroyannidis ${ }^{4,34}$ has reported that polyimides composed of $p$-terphenyl, 1,3,5-triphenylbenzene or triphenylmethane segments

${ }_{\dagger}^{\dagger}$ To whom correspondence should be addressed (E-mail: msato@riko.shimane-u.ac.jp). 


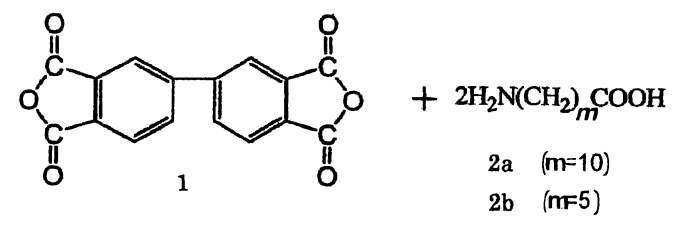<smiles>CCCNC(=O)c1ccc(-c2ccc(C(=O)O)c(C(=O)N(CCC(=O)O)CC(=O)O)c2)cc1C(=O)O</smiles>

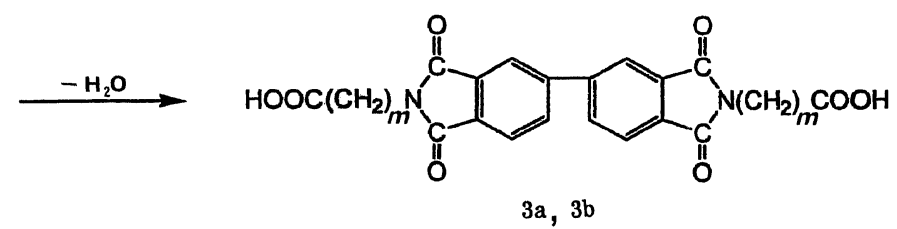<smiles>COC(=O)CN1C(=O)c2ccc(-c3ccc4c(c3)C(=O)N(CCC(C)=O)C4=O)cc2C1=O</smiles>

Scheme 1.

show outstanding thermal stability and photoluminescent (PL) property with blue emission. Pyo et al. have discovered that polypyromellitimide containing quaterphenyl analogue of 2,2' -bifuryl in the main chain shows PL property with blue emission in high quantum yield in film. ${ }^{3}$ We also found that semi-rigid thermotropic LC homopoly(imide carbonate) constituted of $3,3^{\prime \prime}, 4,4^{\prime \prime}$ - $p$-terphenyltetracarboxdiimide shows PL and EL properties with blue emission. ${ }^{35}$ Polymers having the 3,3',4,4'-biphenyltetracarboxdiimide would likely to display PL property arising from the diimide ring and to be candidates for the organic EL devices, because the diimide plays as electron-withdrawing group.

The purpose of this work is to prepare new semirigid homo- and copoly(ester imide)s (6a-1) composed

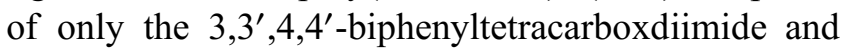
aliphatic spacers $(l=5$ and $6, m=5$ and 10 in Scheme 2) without the traditional mesogenic unit such as the biphenyl moiety in the main chain by melt polycondensation from $N, N^{\prime}$-bismethyl esters (4a) and (4b) and $N, N^{\prime}$-bisalcohol derivatives (5a) and (5b) of 3,3',4,4'-biphenyltetracarboxdiimide and to investigate the mesomorphic and optical properties. It is expected that the semi-rigid poly(ester imide)s (6a-l) in the present work not only form thermotropic LC phases in spite of the absence of the benzene ring or the traditional mesogen in the backbone, but also exhibit PL properties based on the aromatic diimide structure (Schemes 1 and 2).

\section{EXPERIMENTAL}

\section{Materials}

$N, N^{\prime}$-Bis(6-hydroxyhexyl)-3,3',4,4'-biphenyltetracarboxdiimide (5a) and $N, N^{\prime}$-bis(5-hydroxypentyl)$3,3^{\prime}, 4,4^{\prime}$-biphenyltetracarboxdiimide $(5 \mathrm{~b})$ were prepared according to our published methods. ${ }^{19,29}$ $3,3^{\prime}, 4,4^{\prime}$-Biphenyltetracarboxylic dianhydride (1) was purified from acetic anhydride before use. 11Aminoundecanoic acid (2a) and 6-amino- $n$-capronic acid (2b) were commercially available and used after dryness at $60^{\circ}$ for one day in vacuo. Pyridine was purified by distillation under vacuum. $N, N-$ Dimethylformamide (DMF) and 1,4-dioxane were dried over molecular sieve ( $4 \AA$ ).

\section{Synthesis of Monomers (4a) and (4b)}

$N, N^{\prime}$-Bis(10-methoxycarbonyldecyl)-3,3',4,4'-biphenyltetracarboxdiimide (4a). Dianhydride $1(0.025 \mathrm{~mol}$, $7.36 \mathrm{~g})$ and 11-aminoundecanoic acid (2a) $(0.05 \mathrm{~mol}$, $10.07 \mathrm{~g})$ were dissolved in DMF $(30 \mathrm{ml})$ and stirred at 
<smiles>COCCOCCOC(=O)CN1C(=O)c2ccc(-c3ccc4c(c3)C(=O)N(CCOC)C4=O)cc2C1=O</smiles>

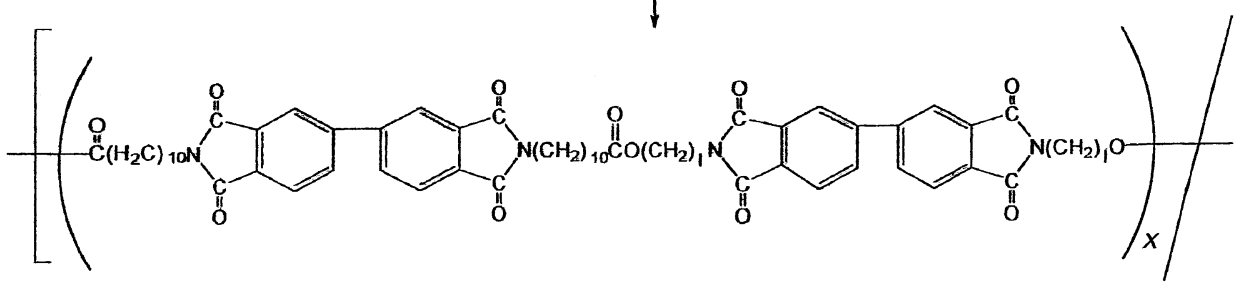

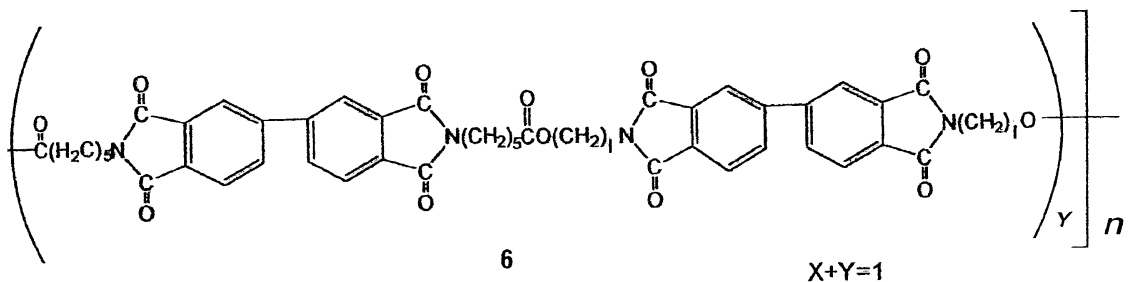

Scheme 2.

room temperature for $24 \mathrm{~h}$. Acetic anhydride $(30 \mathrm{~mL})$ and pyridine $(4 \mathrm{~mL})$ were added into the reaction mixture and refluxed for $20 \mathrm{~h}$. The reaction solution was cooled and poured into an excess of water. The precipitated biscarboxylic acid derivative (3a) was filtered off, washed with thoroughly with water and recrystallized from 1,4-dioxane twice. Subsequently, the derivative (3a) $N, N^{\prime}$-bis(10-carboxydecyl)-3, $3^{\prime}, 4,4^{\prime}$ biphenyltetracarboxdiimide) $(5 \mathrm{mmol}, 3.3 \mathrm{~g})$ was refluxed in a mixture of 1,4-dioxane $(10 \mathrm{~mL})$ and methanol $(30 \mathrm{~mL})$ for $24 \mathrm{~h}$ in the presence of a trace of sulfuric acid as catalyst. After cooling, the separated product was collected by filtration and recrystallized from 1,4-dioxane/methanol $=1 / 3(\mathrm{v} / \mathrm{v})$ twice. Yield; $86 \%$. mp : $107-108^{\circ}$.

$\left(\mathrm{C}_{40} \mathrm{H}_{52} \mathrm{~N}_{2} \mathrm{O}_{8}\right)(688.9)$ Calc. C 69.77 H 7.56 N 4.07. Found C 69.75 H 7.56 N 4.09 .

FT-IR (KBr): $v=2931,2850$ (m, CH stretching), 1732 (s, ester $\mathrm{C}=\mathrm{O}), 1770,1711$ (s, imide $\mathrm{C}=\mathrm{O}), 1620$ (w, C=C), 1393, 1360 (m, imide), 1170 (m, C-O-C), $740 \mathrm{~cm}^{-1}$ ( $\mathrm{m}$, imide ring).

${ }^{13} \mathrm{C} \mathrm{NMR}\left(\mathrm{CDCl}_{3}\right): \delta=174.2($ ester $\mathrm{C}=\mathrm{O}), 168.0$ (imide $\mathrm{C}=\mathrm{O}$ ), 145.1, 133.6, 132.9, 132.0, 124.0, 122.0 (benzene ring), $51.4\left(\mathrm{CH}_{3}\right), 38.3\left(>\mathrm{NCH}_{2}-\right), 34.1$ ($\left.\mathrm{CH}_{2} \mathrm{C}(\mathrm{O}) \mathrm{O}-\right)$, 24.8-29.3 ppm (- $\left.\mathrm{CH}_{2}-\right)$.

$N, N^{\prime}$-Bis(5-methoxycarbonylpentyl)-3,3', 4, 4' biphenyltetracarboxdiimide (4b). The bismethyl ester derivative (4b) was prepared from $N, N^{\prime}$-bis(5carboxypentyl)-3,3' ,4,4' -biphenyltetracarboxdiimide (3b) $(0.01 \mathrm{~mol}, 5.2 \mathrm{~g})$ by the same method as that for (4a). Yield; $88 \%$. mp : $135-137^{\circ} \mathrm{C}$.

$\left(\mathrm{C}_{30} \mathrm{H}_{32} \mathrm{~N}_{2} \mathrm{O}_{8}\right)(548.6)$ Calc. C $65.69 \mathrm{H} 5.84 \mathrm{~N} 5.11$. Found C 65.73 H 5.96 N 5.20.
FT-IR (KBr): $v=2942,2866$ (w, CH stretching), 1770, 1706 (s, imide $\mathrm{C}=\mathrm{O}), 1740$ (s, ester $\mathrm{C}=\mathrm{O}$ ), 1625 (w, C = C), 1397, 1374 (w, imide), 1180 (w, C-OC), $743 \mathrm{~cm}^{-1}$ (w, imide ring).

${ }^{13} \mathrm{C}$ NMR $\left(\mathrm{CDCl}_{3}\right): \delta=174.0($ ester $\mathrm{C}=\mathrm{O}), 167.9$ (imide $\mathrm{C}=\mathrm{O}$ ), 145.1, 133.2, 132.9, 132.1, 124.1, 122.1 (benzene ring), $51.8\left(\mathrm{CH}_{3}\right), 38.1\left(=\mathrm{NCH}_{2}-\right), 34.0$ ($\left.\mathrm{CH}_{2} \mathrm{C}(\mathrm{O}) \mathrm{O}-\right), 28.1,26.2,24.3 \mathrm{ppm}\left(-\mathrm{CH}_{2}-\right)$.

\section{Synthesis of Polymers (6)}

Homopolymers $(6 a, f)$ and $(6 g, l)$. A typical example for the polymer (6a) is described. The $N, N^{\prime}-$ bismethyl ester derivative (4a) $(0.5 \mathrm{mmol}, 0.274 \mathrm{~g})$ and the $N, N^{\prime}$-bisalcohol $(5 \mathrm{a})(0.5 \mathrm{mmol}, 0.246 \mathrm{~g})$ were stirred at $180-185^{\circ} \mathrm{C}$ for $2 \mathrm{~h}$ in the presence of tetraisopropyl orthotitanate in nitrogen. Then the mixture was heated at $190-195^{\circ} \mathrm{C}$ for $1 \mathrm{~h}$ at 15 Torr and finally at $200-205^{\circ} \mathrm{C}$ for $1 \mathrm{~h}$ at a pressure of below 1 Torr. After cooling, the obtained polymer (6a) was dissolved in trifluoroacetic acid (TFAA) and the solution was poured into methanol to reprecipitate the polymer (6a). The precipitated solid was filtered off, washed with water and refluxing methanol three times, and dried at $75^{\circ} \mathrm{C}$ in vacuo for 2 days. Yield, $98 \%$.

$\left(\mathrm{C}_{66} \mathrm{H}_{76} \mathrm{~N}_{4} \mathrm{O}_{12}\right) n,(1117.5) n$, Calc., C $70.93 \mathrm{H} 6.87$ N 5.01. Found, C 70.71 H 6.87 N 5.03.

Homopolymers (6g) and (61) were synthesized under the following polymerization conditions; at $180-185^{\circ}$ for $2 \mathrm{~h}$ under nitrogen, at $190-195^{\circ} \mathrm{C}$ for $1 \mathrm{~h}$ at a pressure of $17-18$ Torr and finally at $200-205^{\circ} \mathrm{C}$ for $1 \mathrm{~h}$ at 2 Torr.

Homopolymer $(6 \mathrm{~g}):\left(\mathrm{C}_{64} \mathrm{H}_{72} \mathrm{~N}_{4} \mathrm{O}_{12}\right) n,(1089.3) n$, Calc., C 70.57, H 6.66, N 5.14. Found, C 71.00, H 
6.39, N 5.13.

\section{Copolymers $(6 b-e)$ and $(6 h-k)$}

The copolymers were prepared by the same method as that of the homopolymer (6a). Copolymers (6be); at $180-185^{\circ} \mathrm{C}$ for $2 \mathrm{~h}$ under nitrogen, at $190-195^{\circ} \mathrm{C}$ for $1 \mathrm{~h}$ at a pressure of 15 Torr and at $200-205^{\circ} \mathrm{C}$ for $1 \mathrm{~h}$ below 1 Torr. Copolymer (6c): $\left(\mathrm{C}_{62} \mathrm{H}_{68} \mathrm{~N}_{4} \mathrm{O}_{12}\right) n$, (1061.3)n, Calc., C 70.16, H 6.47, N 5.28. Found, C 70.09, H 6.37, N 5.32.

Copolymers $(6 \mathrm{~h}-\mathrm{k})$; at $180-185^{\circ} \mathrm{C}$ for $2 \mathrm{~h}$ in nitrogen, at $190-195^{\circ} \mathrm{C}$ for $1 \mathrm{~h}$ at $17-18$ Torr and at 200 $205^{\circ} \mathrm{C}$ for $1 \mathrm{~h}$ at a pressure of 2 Torr. Copolymer (6i): $\left(\mathrm{C}_{58} \mathrm{H}_{60} \mathrm{~N}_{4} \mathrm{O}_{12}\right) n,(1005.1) n$, Calc., C 69.30, H 6.02, N 5.58. Found, C 69.27, H 6.23, N 5.42.

\section{Measurements}

${ }^{13} \mathrm{C}$ NMR spectra were obtained on a JEOL LMN EX270 spectrometer in $\mathrm{CDCl}_{3}$ containing TMS. FT-IR spectra were recorded with a Jasco FT-IR 5300 spectrometer by $\mathrm{KBr}$ disk method. Differential scanning calorimetry (DSC) was performed with a Shimadzu DSC-60 calorimeter in aluminum pans at heating and cooling rates of $10^{\circ} \mathrm{C} \mathrm{m^{-1 }}$ under nitrogen. Optical textures of polymers were observed with a polarizing microscope (Nikon) equipped with a hot plate (magnification: $\times 200)$. Number average molecular weights $\left(\bar{M}_{\mathrm{n}}\right)$ and molecular weight distributions $\left(\bar{M}_{\mathrm{w}} / \bar{M}_{\mathrm{n}}\right)$ were estimated by size exclusion chromatography (SEC) with a Jasco RI-930 refractometer and column in combination (K-803/K-804), using polystyrene standard in chloroform as eluent. Powder X-Ray analysis was carried out by a Rigaku Denki RINT 2500 generator with $\mathrm{Cu}-\mathrm{K} \alpha$ irradiation. UV-vis and PL spectra were obtained on a Jasco V-560 UV/VIS spectrophotometer or Shimadzu UV-vis 3100 spectrophotometer and on a Hitachi 850 fluorescence spectrophotometer, respectively.

\section{RESULTS AND DISCUSSION}

\section{Synthesis of Monomers (4) and Polymers (6)}

New semi-rigid homopoly(ester imide)s (6a, 6f, $6 \mathrm{~g}$ and 6l) composed of only $3,3^{\prime}, 4,4^{\prime}$ biphenyltetracarboxdiimide and aliphatic chains without well-known mesogenic unit like biphenyl were synthesized by transesterification of $N, N^{\prime}$-bismethyl ester derivatives (4a) and (4b) with $N, N^{\prime}$-bisalcohols (5a) and (5b) in the presence of a tetraisopropyl orthotitanate according to the ordinary methods under the polymerization conditions as described in the experimental part. The monomers (4a) $(m=10)$ and $(4 b)(m=5)$ were synthesized by esterification of the corresponding $N, N^{\prime}$-biscarboxylic acids of $3,3^{\prime}, 4,4^{\prime}$-bipheyltetracarboxdiimide (3a) $(m=10)$ and (3b) $(m=5)$ derived from the dianhydride (1) and two aminocarboxylic acids $(2 \mathrm{a})(m=10)$ and $(2 \mathrm{~b})$ $(m=5)$. In addition, copoly(ester imide)s $(6 \mathrm{~b}-\mathrm{e})$ and $(6 \mathrm{~h}-\mathrm{k})$ were prepared by the same procedure as the homopolymers $(6 \mathrm{a}, 6 \mathrm{f}, 6 \mathrm{~g}$, and 61$)$ with a mixture of the monomers (4a) and (4b) and (5a) and (5b) taken in a definite mole ratio. Melt polycondensation proceeded smoothly and afforded the desired semi-rigid poly(ester imide)s (6a-1) with high molecular-weights in high yields. The resulting poly(ester imide)s (6a-1) had very good solubilities in organic solvents such as chloroform, trifluoroacetic acid (TFAA) and dichloroacetic acid, which gave flexible films cast from the chloroform solutions. Their yields, $\bar{M}_{\mathrm{n}}$ and $\bar{M}_{\mathrm{w}} / \bar{M}_{\mathrm{n}}$ are summarized in Table I.

The assigned structures of polymers (6) were checked by ${ }^{13} \mathrm{C}$ NMR and FT-IR spectroscopy, and elemental analyses. The ${ }^{13} \mathrm{C}$ NMR spectra displayed the carbon signals expected for the polymer structures. A typical ${ }^{13} \mathrm{C}$ NMR spectrum of the homopolymer (6a) in $\mathrm{CDCl}_{3}$ illustrated in Figure 1 shows imide $\mathrm{C}=\mathrm{O}$ at $168.1 \mathrm{ppm}$, ester $\mathrm{C}=\mathrm{O}$ at $174.1 \mathrm{ppm}$, carbon atoms of benzene ring at $122-146 \mathrm{ppm},-\mathrm{NCH}_{2}$ at $38.3 \mathrm{ppm}$, $-\mathrm{C}(\mathrm{O}) \mathrm{OCH}_{2}-$ at $64.2 \mathrm{ppm},-\mathrm{OC}(\mathrm{O}) \mathrm{CH}_{2}$-at $34.5 \mathrm{ppm}$ and $-\mathrm{CH}_{2}$ - at $24-30 \mathrm{ppm}$. In the FT-IR spectra of polymers (6), characteristic absorption bands of imide $\mathrm{C}=\mathrm{O}$ at 1710 and $1770 \mathrm{~cm}^{-1}$, shoulder of ester $\mathrm{C}=\mathrm{O}$ around $1730 \mathrm{~cm}^{-1}$, imide ring at 1395,1366 , and $742 \mathrm{~cm}^{-1}$, $\mathrm{CH}$ stretching around 2855 and $2930 \mathrm{~cm}^{-1}, \mathrm{C}=\mathrm{C}$ at $1621 \mathrm{~cm}^{-1}$ and $\mathrm{C}-\mathrm{O}-\mathrm{C}$ at $1173 \mathrm{~cm}^{-1}$ were observed. The elemental analysis data of polymers (6) were in good agreement with the calculated values.

\section{LC Properties of Poly(ester imide)s (6)}

In our previous works, ${ }^{17-30}$ semi-rigid poly(imide carbonate)s composed of the $3,3^{\prime}, 4,4^{\prime}$ biphenyltetracarboxdiimide unit and hexamethylene chain next to the imide ring formed thermotropic LC phases, but polymers having shorter aliphatic (penta- and tetramethylene) chains had no LC melts. ${ }^{29}$ This means that the aliphatic chains next to the imide ring affect the LC formation of the semi-rigid polyimides containing the symmetric diimide rings in the backbone. Moreover, in poly(ester imide)s derived from the $N, N^{\prime}$-bishexanol derivative of $3,3^{\prime}, 4,4^{\prime}$-biphenyltetracarboxdiimide (5a) and aliphatic dimethyl esters, any LC phases were not found. ${ }^{21}$ Therefore, thermal and mesomorphic properties of the corresponding semi-rigid poly(ester imide)s (6) to the above-mentioned poly(imide carbonate) $\mathrm{s}^{29}$ (Scheme 2) were investigated in this work.

Thermotropic LC properties of poly(ester imide)s 
Table I. Yields, $\bar{M}_{\mathrm{n}}$ and $\bar{M}_{\mathrm{w}} / \bar{M}_{\mathrm{n}}$ of polymers (6a-1)

\begin{tabular}{|c|c|c|c|c|c|c|c|c|}
\hline \multirow{2}{*}{$\begin{array}{c}\text { Polym. } \\
\text { No. }\end{array}$} & \multirow{2}{*}{$l$} & \multirow{2}{*}{$\mathrm{x}$} & \multirow{2}{*}{$\mathrm{y}$} & \multirow{2}{*}{$\frac{\text { Yield }}{\%}$} & \multirow{2}{*}{$\bar{M}_{\mathrm{n}}^{\mathrm{a}}$} & \multirow{2}{*}{$\bar{M}_{\mathrm{w}} / \bar{M}_{\mathrm{n}}^{\mathrm{b}}$} & \multicolumn{2}{|c|}{ Solubility $^{\mathrm{c}}$} \\
\hline & & & & & & & $\mathrm{CHCl}_{3}$ & $\mathrm{CH}_{3} \mathrm{OH}$ \\
\hline $6 a$ & 6 & 1.0 & 0 & 98 & 20100 & 2.11 & + & - \\
\hline $6 b$ & 6 & 0.8 & 0.2 & 97 & 20000 & 2.18 & + & - \\
\hline $6 c$ & 6 & 0.6 & 0.4 & 99 & 22100 & 2.12 & + & - \\
\hline $6 \mathrm{~d}$ & 6 & 0.4 & 0.6 & 94 & 23400 & 2.13 & + & - \\
\hline $6 e$ & 6 & 0.2 & 0.8 & 96 & 21800 & 2.05 & + & - \\
\hline $6 f$ & 6 & 0 & 1.0 & 96 & 20500 & 2.07 & + & - \\
\hline $6 \mathrm{~g}$ & 5 & 1.0 & 0 & 96 & 21300 & 2.13 & + & - \\
\hline $6 \mathrm{~h}$ & 5 & 0.8 & 0.2 & 97 & 12900 & 2.07 & + & - \\
\hline $6 \mathrm{i}$ & 5 & 0.6 & 0.4 & 94 & 45500 & 3.50 & + & - \\
\hline $6 \mathrm{j}$ & 5 & 0.4 & 0.6 & 89 & 19600 & 2.15 & + & - \\
\hline $6 \mathrm{k}$ & 5 & 0.2 & 0.8 & 86 & 14600 & 1.81 & + & - \\
\hline 61 & 5 & 0 & 1.0 & 95 & 19600 & 1.87 & + & - \\
\hline
\end{tabular}

a $\bar{M}_{\mathrm{n}}$ : number-average molecular weight estimated by SEC using chloroform as solvent and polystyrene as standard.

b $\bar{M}_{\mathrm{w}} / \bar{M}_{\mathrm{n}}$ : molecular weight distribution. ${ }^{\mathrm{c}}+$ : soluble at room temperature. - : insoluble.
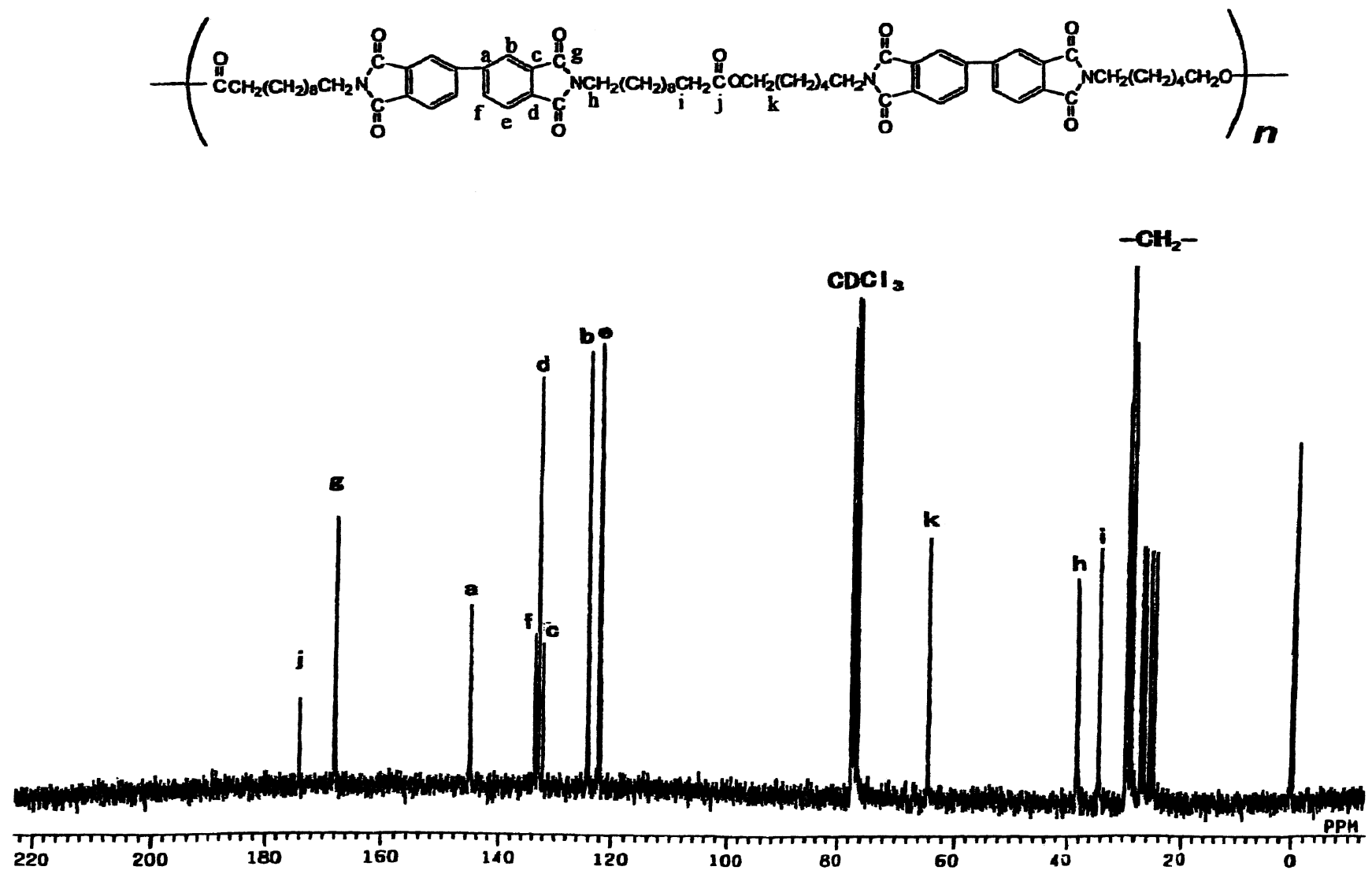

Figure 1. ${ }^{13} \mathrm{C}$ NMR spectrum of polymer (6a) in $\mathrm{CDCl}_{3}$.

(6) were evaluated by means of DSC measurements, optical microscopy and powder X-Ray analyses. In the DSC curves of polymers (6a-f) having hexamethylene chain $(l=6)$ neighboring the imide ring, two or three endothermal peaks based on solid-to-solid $\left(T_{\mathrm{k}_{1}}\right.$ and $\left.T_{\mathrm{k}_{2}}\right)$, solid-to-LC phase $\left(T_{\mathrm{m}}\right)$ and LC phaseto-isotropization temperatures $\left(T_{\mathrm{i}}\right)$ together with glass transition temperatures $\left(T_{\mathrm{g}}\right)$ were observed in the first heating scans, but in the second heating runs only the homopolymer (6a) having decamethylene and hexam- ethylene chains ( $m=10, l=6)$, and decamethylene chain-rich copolymer (6b) showed two endothermal peaks due to $T_{\mathrm{m}}\left(155^{\circ} \mathrm{C}\right.$ and $\left.150^{\circ} \mathrm{C}\right)$ and $T_{\mathrm{i}}\left(171^{\circ} \mathrm{C}\right.$ and $\left.161^{\circ} \mathrm{C}\right)$ in addition to the $T_{\mathrm{g}}\left(39^{\circ} \mathrm{C}\right.$ and $\left.44^{\circ} \mathrm{C}\right)$ steps. The others had no endotherms even after annealing for $12 \mathrm{~h}$ above Tg temperatures. In the first cooling runs, only the homopolymer (6a) showed two exotherms based on isotropization-to-LC phase $\left(T_{\mathrm{i}}\right)$ at $140^{\circ} \mathrm{C}$ and LC phase-to-solid $\left(T_{\mathrm{c}}\right)$ at $120^{\circ} \mathrm{C}$, but the polymers $(6 \mathrm{c}-\mathrm{f})$ still displayed no exothermal peaks. 


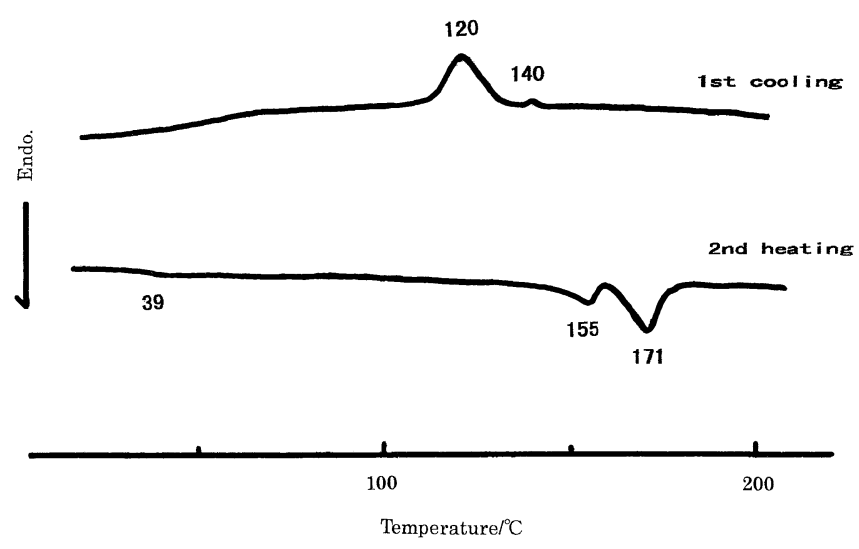

Figure 2. DSC curves of polymer (6a) in the first cooling and the second heating runs.

Polarizing microscope observations showed that the homopolymer (6a) with the decamethylene chain and decamethylene chain-rich copolymer (6b), whose DSC curve was observed with difficulty in the cooling run, form nematic phase between $T_{\mathrm{m}}$ (or $T_{\mathrm{c}}$ ) and $T_{\mathrm{i}}$. The DSC curves of homopolymer (6a) $(m=10, l=6)$ are shown in Figure 2 and the polarizing microphotograph for homopolymer (6a) at $140^{\circ}$ on the first cooling is presented in Figure 3. On the other hand, the DSC curves of poly(ester imide)s $(6 \mathrm{~g}-1)$ with pentamethylene chain next to the imide ring showed two or three endotherms $\left(T_{\mathrm{k}_{1}}, T_{\mathrm{k}_{2}}, T_{\mathrm{m}}\right.$ and $\left.T_{\mathrm{i}}\right)$ in addition to the $T_{\mathrm{g}}$ steps in the first heating runs as the above-described poly(ester imide)s (6a-f) having the hexamethylene chain. But in the first cooling and in the second heating, exo- and endothermal peaks were not recognized even after annealing above $T_{\mathrm{g}}$ by $10-20^{\circ} \mathrm{C}$ for $12 \mathrm{~h}$. The polarizing microscope observations described that homopolymer (6g) with decamethylene and pentamethylene chains ( $m=10, l=5$ ) and decamethylene chain-rich copolymers (6h) and (6i) show stir-opalescence on the first cooling and on the second heating, whereas the nematic schlieren or thread texture was observed with difficulty. Powder X-Ray analyses of polymers (6) quenched from the LC state supported that these polymers (6a) and (6b) and $(6 \mathrm{~g}-\mathrm{i})$ form nematic phase, where broad reflections at $\theta=20-26^{\circ}$ and no reflections at small angles were observed as shown in Figure 4. The phase transition data for polymers $(6 \mathrm{a}-\mathrm{f})$ and $(6 \mathrm{~g}-1)$ are listed in Table II. The temperatures $\left(T_{\mathrm{m}}\right.$ and $\left.T_{\mathrm{i}}\right)$ for the polymers (6a) and (6b) tend to be higher than those for the polymers $(6 \mathrm{~g}-\mathrm{i})$ and their $T_{\mathrm{g}}$ steps decreased with increase of the decamethylene contents.

From these data, it is suggested that the mesogenic property of $3,3^{\prime}, 4,4^{\prime}$-biphenyltetracarboxdiimide is still low as previouslyreported ${ }^{21}$ and only a part of polymers (6a) and (6b) and (6g-i) form nematic phase. The homopolymer (6a) having the decamethylene chain

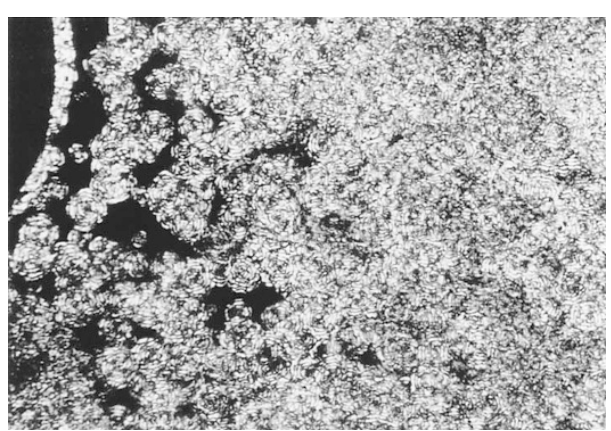

Figure 3. Polarizing microphotograph of polymer (6a) at $140^{\circ} \mathrm{C}$ in the cooling (magnification $\times 200$ ).

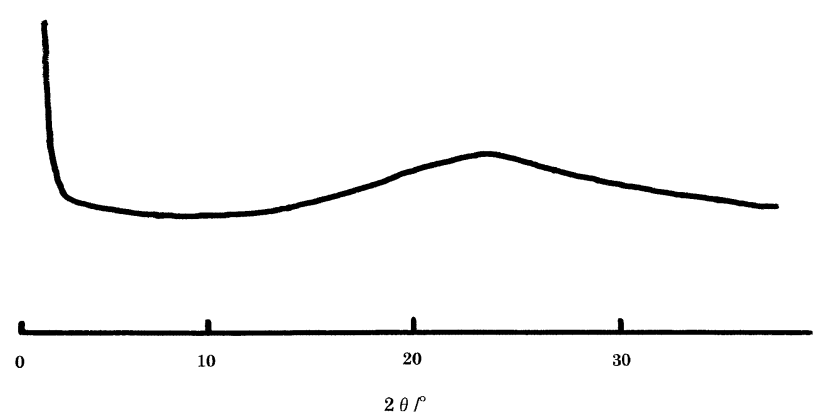

Figure 4. X-Ray diffraction pattern of polymer (6i).

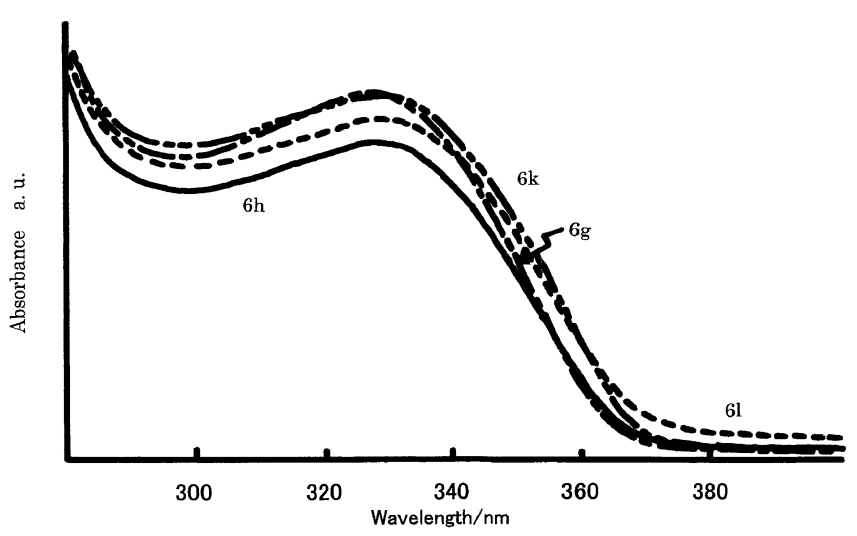

Figure 5. UV-vis absorption spectra of polymers $(6 \mathrm{~g}, 6 \mathrm{~h}, 6 \mathrm{k}$, and 61) in films.

and the decamethylene chain-rich copolymer (6b) form clearer LC texture than the homo- and copolymers $(6 \mathrm{~g}-$ i) comprising the pentamethylene chain. It is probably due to that the former is constituted of two aliphatic spacers with odd numbers between two imide rings in the repeating unit and the total lengths of two aliphatic chains are odd numbers, where linearity of polymer chain is not disturbed and the LC ordered structure is retained. On the other hand, the latter has aliphatic chains with even number disturbing the alignment of polymer chains. ${ }^{12}$ The introduction of aliphatic chain of even number and the combination of chains with even and odd numbers in the polymer backbone seem to favor the formation of amorphous and no LC states in these polymers. 
Table II. Phase transition temperatures of polymers $(6 \mathrm{a}-1)^{\mathrm{a}}$

\begin{tabular}{ccccccccc}
\hline $\begin{array}{l}\text { Polym. } \\
\text { No. }\end{array}$ & $\frac{T_{\mathrm{g}}^{\mathrm{b}}}{{ }^{\circ} \mathrm{C}}$ & $\frac{T_{\mathrm{k}_{1}}}{{ }^{\circ} \mathrm{C}}$ & $\frac{T_{\mathrm{k}_{2}}}{{ }^{\circ} \mathrm{C}}$ & $\frac{T_{\mathrm{c}}}{{ }^{\circ} \mathrm{C}}$ & $\frac{T_{\mathrm{m}}}{{ }^{\circ} \mathrm{C}}$ & $\frac{T_{\mathrm{i}}}{{ }^{\circ} \mathrm{C}}$ & $\frac{\Delta T}{{ }^{\circ} \mathrm{C}}$ & Mesophase \\
\hline $6 \mathrm{a}^{\mathrm{b}}$ & 39 & - & - & - & 155 & 171 & 16 & Nematic \\
$6 \mathrm{~b}^{\mathrm{b}}$ & 44 & - & - & 113 & 150 & 161 & 11 & Nematic \\
$6 \mathrm{c}$ & 51 & 110 & - & - & 142 & - & - & - \\
$6 \mathrm{~d}$ & 56 & 117 & - & - & 137 & - & - & - \\
$6 \mathrm{e}$ & 61 & 116 & 145 & - & 163 & - & - & - \\
$6 \mathrm{f}$ & 67 & 111 & 150 & - & 174 & - & - & - \\
$6 \mathrm{~g}^{\mathrm{b}}$ & 46 & 84 & - & - & 120 & 134 & 14 & Nematic \\
$6 \mathrm{~h}^{\mathrm{b}}$ & 44 & - & - & - & 104 & 123 & 19 & Nematic \\
$6 \mathrm{i}^{\mathrm{b}}$ & 53 & - & - & - & 115 & 137 & 18 & Nematic \\
$6 \mathrm{j}$ & 60 & 115 & - & - & 138 & - & - & - \\
$6 \mathrm{k}$ & 71 & 123 & 143 & - & 171 & - & - & - \\
61 & 74 & 126 & 147 & - & 174 & - & - & - \\
\hline
\end{tabular}

${ }^{\text {a } D a t a}$ observed on the first heating scans. $T_{\mathrm{g}}$ : glass transition temperature; $T_{\mathrm{k}_{1}}$ and $T_{\mathrm{k}_{2}}:$ solid-to-solid transition temperature; $T_{\mathrm{c}}$ : crystallization temperature; $T_{\mathrm{m}}$ : melting temperature; $T_{\mathrm{i}}$ : isotropization temperature; $\Delta T=T_{\mathrm{i}}-T_{\mathrm{m}}$ : temperature range of LC phase. ${ }^{\mathrm{b}}$ Data observed on the second heating scans.

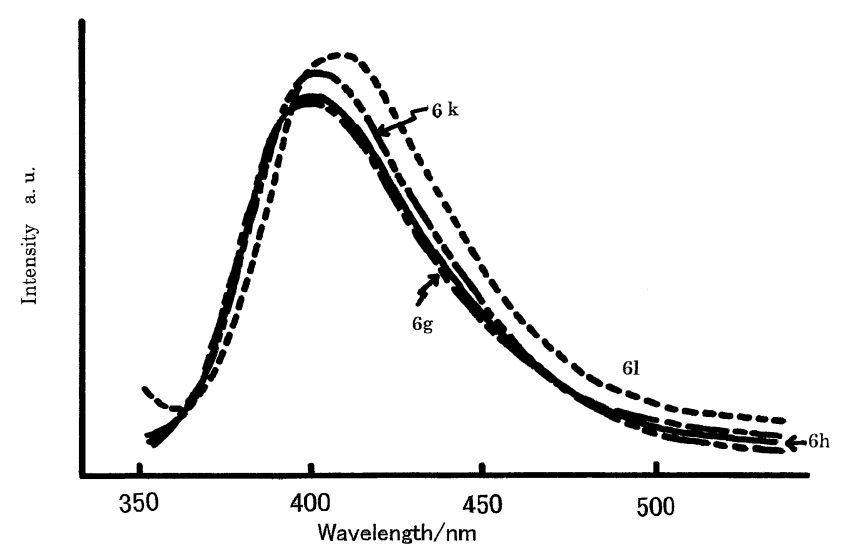

Figure 6. PL spectra of polymers $(6 \mathrm{~g}, 6 \mathrm{~h}, 6 \mathrm{k}$, and 61$)$ in films.

\section{Optical Properties of Polymers (6)}

UV-vis absorption and PL spectra of the $3,3^{\prime}, 4,4^{\prime}$ biphenyltetracarboxdiimide-containing homo- and copoly(ester imide)s (6) in chloroform solutions and in films cast from the chloroform solutions were investigated. The UV-vis spectra of polymers (6) in the chloroform solutions showed absorption peak maxima around $325 \mathrm{~nm}$ due to the $3,3^{\prime}, 4,4^{\prime}$ biphenylcarboxdiimide unit and were almost similar to those showing peak maxima at $328-330 \mathrm{~nm}$ in the films. Figure 5 displays typical UV-vis spectra of polymers (6) in the films. In the PL spectra of polymers (6) in the chloroform solutions blue-emission maxima were observable around $388 \mathrm{~nm}$ (excited at 323-325 nm). As shown in Figure 6, in the PL spectra in the films the polymers exhibited peak maxima around $400 \mathrm{~nm}$ with blue emission when excited at 328-330 nm, which were red-shifted to lower energies compared to the data in the solutions, indicating occurrence of intermolecular aggregation effect. ${ }^{36}$ All the PL spectra in the solutions and in the films showed emission tail at longer wavelength, probably due to intramolecular interactions among the biphenyl and the imide ring. ${ }^{4}$ These data suggest that the polymers (6) in this study have potential as the materials for the organic EL devices.

\section{CONCLUSIONS}

Organic-soluble and high molecular-weight semirigid poly(ester imide)s (6) containing only $3,3^{\prime}, 4,4^{\prime}$ biphenyltetracarboxdiimide and aliphatic chains without well-known biphenyl mesogen in the backbone were prepared by melt polycondensation in high yields. Only a part of polymers having decamethylene chain next to the imide ring and decamethylene chain-rich copolymers formed nematic phase, indicating that aliphatic chains with odd numbers next to the imide ring and between two imide rings in the repeating unit play an important role in LC formation of the semi-rigid poly(ester imide)s. These polymers blue-fluoresced in films, which suggested that they are candidate materials for organic EL devices.

Acknowledgment. The authors are grateful to Ms. Michiko Egawa for her help in obtaining elemental analysis data.

\section{REFERENCES}

1. M. Sato, "Handbook of Thermoplastics", O. Olabisi, Ed., Marcel Dekker, New York, N.Y., 1997, p 665.

2. A. Greiner and H.-W. Schmidt, in "Handbook of Liquid Crystals", vol.3, D. Demus, J. Goodby, G. W. Gray, H.-W. speiss, and V. Vill, Ed., John Wiley \& Sons, Inc., New York, N.Y., 1998. p 3 . 
3. S. M. Pyo, S. I. Kim, T. J. Shin, H. K. Park, M. Ree, K. H. Park, and J. S. Kang, Macromolecules, 31, 4777 (1998).

4. J. A. Mikroyannidis, Macromol. Chem. Phys., 200, 2327 (1999).

5. Abajo, J. G. Campa, H. R. Kricheldorf, and G. Schwarz, Makromol. Chem., 191, 537 (1990).

6. J. Abajo, J. G. Campa, H. R. Kricheldorf, and G. Schwarz, Polymer, 35, 5577 (1994).

7. R. Pardey, A. Zheng, P. A. Gabori, F. W. Harris, S. Z. D. Cheng, J. M. Adduci, J. V. Facinelli, and R. W. Lenz, Macromolecules, 25, 5060 (1992).

8. J. M. Adduci, J. V. Facinelli, and R. W. Lenz, J. Polym. Sci., Part A: Polym. Chem., 32, 2931 (1994).

9. H. R. Kricheldorf, G. Schwarz, M. Berghan, J. Abajo, and J. G. Campa, Macromolecules, 27, 2540 (1994).

10. H. R. Kricheldorf and M. Berghan , J. Polym. Sci., Part A: Polym. Chem., 33, 427 (1995).

11. H. R. Kricheldorf, V. Linzer, J. Abajo, and J. G. Campa, J. Macromol. Sci., Pure Appl. Chem., A32, 311 (1995).

12. H. R. Kricheldorf, N. Probst, G. Schwarz, and C. Wutz, Macromolecules, 29, 4234 (1996).

13. H. R. Kricheldorf, M. Rabenstein, and G. Schwarz, J. Polym. Sci., Part A: Polym. Chem., 38, 3019 (2000).

14. H. R. Kricheldorf, D. Gieseler, and M. Rabenstein, J. Macromol. Sci., Pure Appl. Chem., A37, 893 (2000).

15. T. Inoue, M. Kakimoto, Y. Imai, and J. Watanabe, Macromolecules, 28, 6368 (1995)

16. T. Inoue, M. Kakimoto, Y. Imai, and J. Watanabe, Macromol. Chem. Phys., 198, 519 (1997).

17. M. Sato, T. Hirata, and K. Mukaida, Makromol. Chem., 193, 1729 (1992).

18. T. Hirata, M. Sato, and K. Mukaida, Makromol. Chem., 194, 2861 (1993).

19. T. Hirata, M. Sato, and K. Mukaida, Macromol. Chem. Phys.,
195, 1611 (1994).

20. T. Hirata, M. Sato, and K. Mukaida, Macromol. Chem. Phys., 195, 2267 (1994).

21. M. Sato, T. Hirata, and K. Mukaida, Macromol. Rapid Commun., 15, 203 (1994).

22. M. Sato, T. Hirata, and K. Mukaida, Eur. Polym. J., 32, 639 (1996).

23. M. Sato, T. Hirata, T. Kamita, and K. Mukaida, High Perform. Polym., 7, 347 (1995).

24. M. Sato, T. Hirata, and S. Ujiie, Macromol. Chem. Phys., 197, 1983 (1996).

25. M. Sato, T. Hirata, and S. Ujiie, React. Func. Polym., 30, 93 (1996).

26. M. Sato, S. Ujiie, and T. Hirata, Macromol. Chem. Phys., 197, 2765 (1996).

27. M. Sato, S. Ujiie, Y. Tada, and T. Kato, High Perform. Polym., 10, 155 (1998).

28. M. Sato and A. Kogawa, Liq. Cryst., 27, 1123 (2000).

29. M. Sato and A. Kogawa, Eur. Polym. J., 37, 1151 (2001).

30. M. Sato and Y. Nakamoto, to be submitted.

31. N. C. Greenham and R. H. Friend, "Solid State Physics", vol.49, H. Enhrenreich and F. Spaepen, Ed., Academic Press, New York, N.Y., 1995, p 1.

32. P. Chandrasekhar, Ed., "Conducting Polymers, Fundamentals and Applications: A Practical Approach", Kluwer Academic Publishers, Boston, CT, 1999.

33. J. H. Burroughes, D. D. C. Bradley, A. R. Brown, R. N. Marks, K. Mackay, R. H. Friend, P. L. Burn, and A. B. Holmes, Nature, 347, 539 (1990).

34. I. K. Spiliopoulos and J. A. Mikroyannidis, Macromolecules, 31, 515 (1998).

35. M. Sato, A. Kogawa, Y. Nakamoto, R. Ishii, J. Kido, and K. Yonetake, Polym. Prepr. Jpn., 50, 869 (2001).

36. E. Conwell, Trends Polym. Sci., 7, 218 (1997). 